Original Research Paper

\title{
Progressive LDL Reduction to Very Low Levels Improves Dimeric Nitric Oxide Synthase, Nitric Oxide Bioavailability and Reduces Peroxynitrite in Endothelial Cells during Hyperglycemia
}

\author{
${ }^{1,3}$ R. Preston Mason, ${ }^{2}$ Hazem Dawoud, \\ ${ }^{3}$ Samuel C.R. Sherratt, ${ }^{2}$ Michael R. Wagner and ${ }^{2}$ Tadeusz Malinski \\ ${ }^{I}$ Brigham and Women's Hospital, Harvard Medical School, Boston, MA, USA \\ ${ }^{2}$ Nanomedical Research Laboratory, Ohio University, Athens, OH, USA \\ ${ }^{3}$ Elucida Research LLC, Beverly, MA, USA
}

\author{
Article history \\ Received: 17-01-2019 \\ Revised: 08-04-2019 \\ Accepted: 30-04-2019 \\ Corresponding Author: \\ Tadeusz Malinski \\ Nanomedical Research \\ Laboratory, Ohio University, \\ Athens, OH, USA \\ Tel: 740-597-4217 \\ Email: Malinski@ohio.edu
}

\begin{abstract}
Circulating levels of glucose and LDL influence Endothelial Cell (EC) function in a highly interactive manner as evidenced by nitric oxide production and coupling of endothelial Nitric Oxide Synthase (eNOS) dimer. Here, we report on the status of eNOS function in Human Umbilical Vein Endothelial Cells (HUVECs) cultured under normo- and hyperglycemic (250 $\mathrm{mg} / \mathrm{dL}$ ) condition followed by exposure to increasing LDL concentrations (10-150 mg/dL). Production of bioavailable, cytoprotective NO and cytotoxic peroxynitrite $\left(\mathrm{ONOO}^{-}\right)$were measured in endothelium with nanosensors. Coupling efficiency of dimeric eNOS was measured using immunochemistry. The ratio of cytoprotective $\mathrm{NO}$ and cytotoxic ONOO'concentrations ([NO]/[ONOO$\left.{ }^{-}\right]$) was used as a marker for eNOS and endothelial function. The normal ratio for $[\mathrm{NO}] /\left[\mathrm{ONOO}^{-}\right]$is $2.5-5.0$. A ratio of 1.0 or below is an indicator of modest to severe endothelial dysfunction. Under normoglycemic conditions (up to $100 \mathrm{mg} / \mathrm{dL}$ glucose) $[\mathrm{NO}] /\left[\mathrm{ONOO}^{-}\right]$can reach the 0.50 value with the LDL concentration of about $110 \mathrm{mg} / \mathrm{dL}$, while in hyperglycemia ( $250 \mathrm{mg} / \mathrm{dL}$ glucose), the 0.50 value was reached at about 50 $\mathrm{mg} / \mathrm{dL}$. Reduction of LDL down to $50 \mathrm{mg} / \mathrm{dL}$, in hyperglycemia, helps prevent severe dysfunction in endothelium by enhancing eNOS dimerization, increasing NO production and decreasing the concentration of cyctotoxic $\mathrm{ONOO}^{-}$, which may significantly reduce CV risk factors.
\end{abstract}

Keywords: Endothelium, LDL, Nitric Oxide Synthase, Hyperglycemia

\section{Introduction}

As a Cardiovascular (CV) risk factor, Diabetes Mellitus (DM) confers more than a two-fold increase in absolute adjusted risk of CV death. There is also a log linear relationship between cholesterol levels and CV death for subjects with DM that is independent of baseline LDL levels (Stamler et al., 1993). The Collaborative Atorvastatin Diabetes Study (CARDS) demonstrated that patients with type 2 diabetes and other risk factors for CVD benefited from statin treatment regardless of their baseline LDL level (Colhoun et al., 2004). The Cholesterol Treatment Trialists (CTT) Collaborators showed a significant reduction in $\mathrm{CV}$ events with statin therapy in individuals with DM even without other risk factors (Cholesterol Treatment Trialists et al., 2008). Beyond LDL reductions, certain benefits of statins may be attributed to pleiotropic mechanisms (Bonetti et al., 2003; Consentino et al., 2002; Mason et al., 2005a). Of particular interest, statins increase the levels of eNOS and NO production, a regulator of thrombus development and endothelial function (Laufs et al., 1998; Mason et al., 2008; Treasure et al., 1995). As a result of the clinical evidence, ADA guidelines indicate that individuals with DM should be treated with a statin for primary and secondary prevention of cardiovascular events.

While statins have had a major impact on reducing the burden of atherosclerotic disease, there is still substantial CVD risk, especially in higher risk subjects, such as those with DM (Fruchart et al., 2014). For this 
reason, there is now emerging clinical evidence that further reductions in LDL, below optimal levels (considered to be $70 \mathrm{mg} / \mathrm{dL}$ ), may provide additional reductions in CVD risk. With the recent availability of PCSK-9 inhibitors like evolocumab for intensive LDL reduction beyond statins, this hypothesis was recently addressed in the FOURIER trial (Sabatine et al., 2017). With over 27,000 subjects, it found that reducing LDL levels to an average of $30 \mathrm{mg} / \mathrm{dL}$ using evolocumab was associated with an overall $15-20 \%$ CVD risk reduction in an incremental manner.

Individuals with DM are at higher risk for atherosclerosis, a disease process characterized by inflammation, oxidative stress and EC dysfunction (Cavender et al., 2015; Harrison et al., 1987; Liao, 1998; Oemar et al., 1998; Williams et al., 1996). EC dysfunction is observed in patients and animal models of diabetes and indicated by a loss of NO release (Kurioka et al., 2000; Mason et al., 2009; Node et al., 1997). The net concentration of NO in the circulation is dependent on the balance between the enzymatic production of NO through the activity of eNOS and the production of superoxide $\left(\mathrm{O}_{2}{ }^{-}\right)$(Harrison, 1997; Dawoud and Malinski, 2018). Attenuated NO release contributes to platelet aggregation, leukocyte adhesion and loss of normal vasodilation (Paniagua et al., 2001; Panza et al., 1990). When the levels of co-factors are insufficient, the dimeric form of eNOS is uncoupled and there is a reduction of molecular oxygen, followed by the oxidation of $\mathrm{L}$-arginine. This results in the concomitant generation of $\mathrm{O}_{2}^{-}$and $\mathrm{NO}$, which can react rapidly to produce cytotoxic $\mathrm{ONOO}^{-}$ (Harrison, 1997; Mason et al., 2009; Node et al., 1997). In this study, we tested the hypothesis that LDL reductions below $70 \mathrm{mg} / \mathrm{dL}$ enhance endothelial NO bioavailability in a progressive manner due to improved coupling efficiency of dimeric eNOS, while simultaneously decreasing the production of cytotoxic $\mathrm{ONOO}^{-}-$a main component of oxidative stress. We tested this hypothesis with the simultaneous in situ measuring of NO and $\mathrm{ONOO}^{-}$release in human ECs exposed to high and normal glucose concentrations, as well as monitoring eNOS dimerization via immunochemistry under both LDL and glycemic conditions. The results provide new insights into the relationship between cellular NO release, eNOS coupling and LDL levels under normal and hyperglycemic conditions.

\section{Materials and Methods}

\section{Materials}

LDL was isolated from healthy volunteers.

\section{Cell Culture}

Primary human umbilical vein endothelial cells (HUVECs; Lonza, Walkersville, MD) were cultured in complete EC growth medium and incubated at $37^{\circ} \mathrm{C}$ in
$95 \%$ air/ $5 \% \quad \mathrm{CO}_{2}$ according to the distributor's recommendations. Medium was replaced every other day and cells were propagated using a tryptic procedure. Before amperometric measurement of $\mathrm{NO} / \mathrm{ONOO}^{-}$, cells were exposed to LDL ( 150 to $<10 \mathrm{mg} / \mathrm{dL})$ at either normal glucose or elevated glucose levels for 1 hour.

\section{NO and $\mathrm{ONOO}^{-}$Measurement}

$\mathrm{NO}$ and $\mathrm{ONOO}^{-}$release were measured from the surface of a monolayer of ECs using amperometric nanosensors as previously described (Malinski and Taha, 1992; Mason et al., 2005b). Carbon fibers were fed through pulled capillaries and coupled to copper wire using conductive silver epoxy (EpoTek). The exposed tip of the fiber was insulated with nonconductive wax epoxy and flame sharpened to produce an electroactive sensing tip (4-5 $\mu \mathrm{m}$ length, 200-300 $\mathrm{nm}$ diameter). The tip was then chemically modified by depositing conductive polymeric porphyrinic films via cyclic voltammetry on a Gamry 600 potentiostat (Gamry Instruments, Warminster, PA). For NO nanosensors, the sensing material deposited was nickel (II) tetrakis (3-methyl-4hydroxyphenyl) porphyrin, while $\mathrm{ONOO}^{-}$nanosensors were modified with manganese (III) $[2,2]$ paracyclophenyl porphyrin. Finally, ion exchangers were dip coated on the sensors surface to reduce interference of measuring the analyte; Nafion (Sigma) was used for the NO nanosensor and polyvinyl pyridine for $\mathrm{ONOO}^{-}$nanosensor. Electrodes were calibrated by linear regression with standard solutions of both $\mathrm{NO}$ and $\mathrm{ONOO}^{-}$ before and after cellular measurements and the detection limit of each electrode was on the order of $10^{-9} \mathrm{M}$.

Finished nanosensor tandems were lowered $5 \pm 2 \mu \mathrm{m}$ from the surface of the ECs in HBSS using a micromanipulator (Sensapex, Finland) and $\mathrm{NO}^{-\mathrm{ONOO}^{-}}$ release was stimulated with calcium ionophore A21387 (CaI, $1 \mu \mathrm{mol} / \mathrm{L})$. Amperometric responses were obtained using a Gamry Reference 600 dual potentiostat (Gamry Instruments, Warminster, PA).

\section{Western Blot Analysis}

Mouse anti-eNOS antibody and HRP goat anti-mouse Ig were purchased from BD Biosciences, San Jose, CA). Anti-B-actin was purchased from Sigma (St. Louis, MO). RIPA lysis buffer was purchased from Santa Cruz Biotechnology (Santa Cruz, CA). Dimeric eNOS was detected with Western blot using SDS-PAGE at low temperature (LT-SD-PAGE) as previously described (Benson et al., 2013). Briefly, after treatments cells were lysed with RIPA buffer supplemented with protease inhibitor at $4^{\circ} \mathrm{C}$. Protein lysate were mixed 1:1 with Laemmli buffer and loaded onto a $6 \%$ polyacrylamide gel and subjected to SDS-PAGE with at low temperature. After electrophoresis, proteins were transferred onto Polyvinyl Difluoride (PVDF) membrane 
at $4{ }^{\circ} \mathrm{C}$ overnight. Following the transfer, membranes were incubated with $5 \%$ non-fat milk /TBSP blocking buffer for $2 \mathrm{~h}$ at room temperature and washed three times in TBST buffer. Blots were incubated with antieNOS antibody at $4^{\circ} \mathrm{C}$ overnight and washed with TBST three times before conjugation with the secondary HRP-IgG antibody for 1.5 hours at room temperature. Blots were washed and visualized using enhanced chemiluminescence (ChemiDoc MP System; Bio-Rad Laboratories, Inc., Hecules, CA, USA) and analyzed and quantified using Image Lab Version 5.2.1; Bio-Rad Laboratories, Inc.).

\section{Calculations and Statistical Analysis}

All data are presented as mean \pm Standard Deviation (SD) of the mean of $n>3$. Statistical analysis of the mean difference between multiple groups was performed using one-way Analysis of Variance (ANOVA) with StudentNewman-Keuls multiple comparisons post hoc analysis; and between two groups, using Student's $t$-test. The alpha level for all the tests was 0.05 . A P value $<0.05$ was considered to be statistically significant. All statistical analyses were performed using Origin (v 6.1 for Windows; OriginLab, Northampton, MA) and
GraphPad Prism (v. 5.00 for Windows; GraphPad Software, San Diego, CA).

\section{Results}

\section{Nitric Oxide and Peroxynitrite Release from Endothelium}

Figure 1 shows a typical amperogram (concentration proportional to current vs. time) recorded by NO and $\mathrm{ONOO}^{-}$nanosensors, positioned about $5 \pm 2 \mu \mathrm{m}$ from the surface of the HUVECs. After stimulation by calcium ionophore, a rapid release of both [NO] and [ONOO$\left.{ }^{-}\right]$ was observed (Fig. 1). After about 2-5 seconds, maximum concentration was reached, followed by a gradual decrease in both [NO] and [ONOO$\left.{ }^{-}\right]$. In the presence of LDL, maximum [NO] decreased vs. control by about $30 \%$. A further decrease in maximal [NO] was observed for HUVECs treated with both LDL and elevated glucose (Fig. 1a). The change in maximal $\left[\mathrm{ONOO}^{-}\right]$were opposite of that observed for [NO]. In the presence of $\mathrm{LDL}$, maximal [ONOO$\left.{ }^{-}\right]$increased by about $25-35 \%$. A further significant increase in $\left[\mathrm{ONOO}^{-}\right]$was also observed in the presence of elevated glucose (250 $\mathrm{mg} / \mathrm{dL}$ ) and LDL (30 mg/dL) (Fig. 1b).
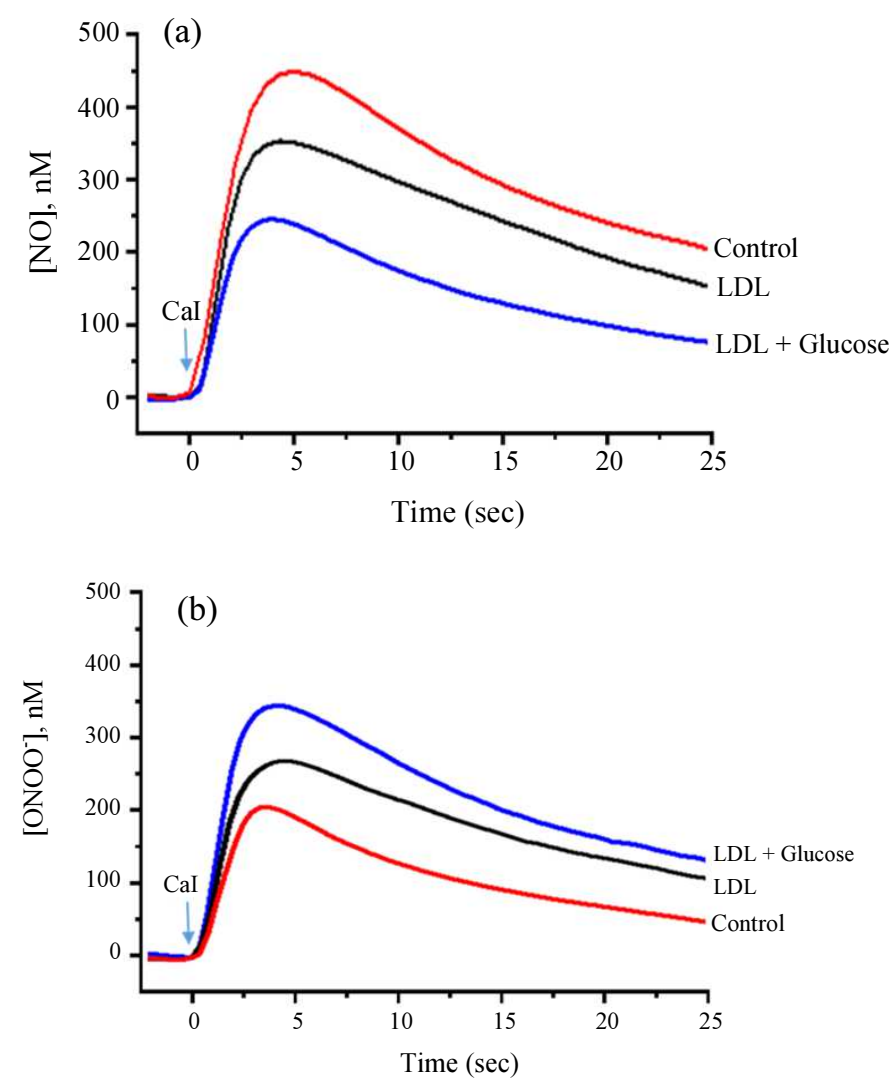

Fig. 1: Typical amperogram showing changes of nitric oxide concentrations [NO] (a) and peroxynitrite concentrations [ONOO- $]$ (b), with time. $\mathrm{NO}$ and $\mathrm{ONOO}^{-}$production was measured simultaneously with nanosensors after stimulation with calcium ionophore (CaI, 1.0 $\mu \mathrm{M})$. HUVECs were incubated with LDL $(30 \mathrm{mg} / \mathrm{dL})$ or with LDL $(30 \mathrm{mg} / \mathrm{dL})$ and elevated glucose $(250 \mathrm{mg} / \mathrm{dL})$ for $1 \mathrm{~h}$ 

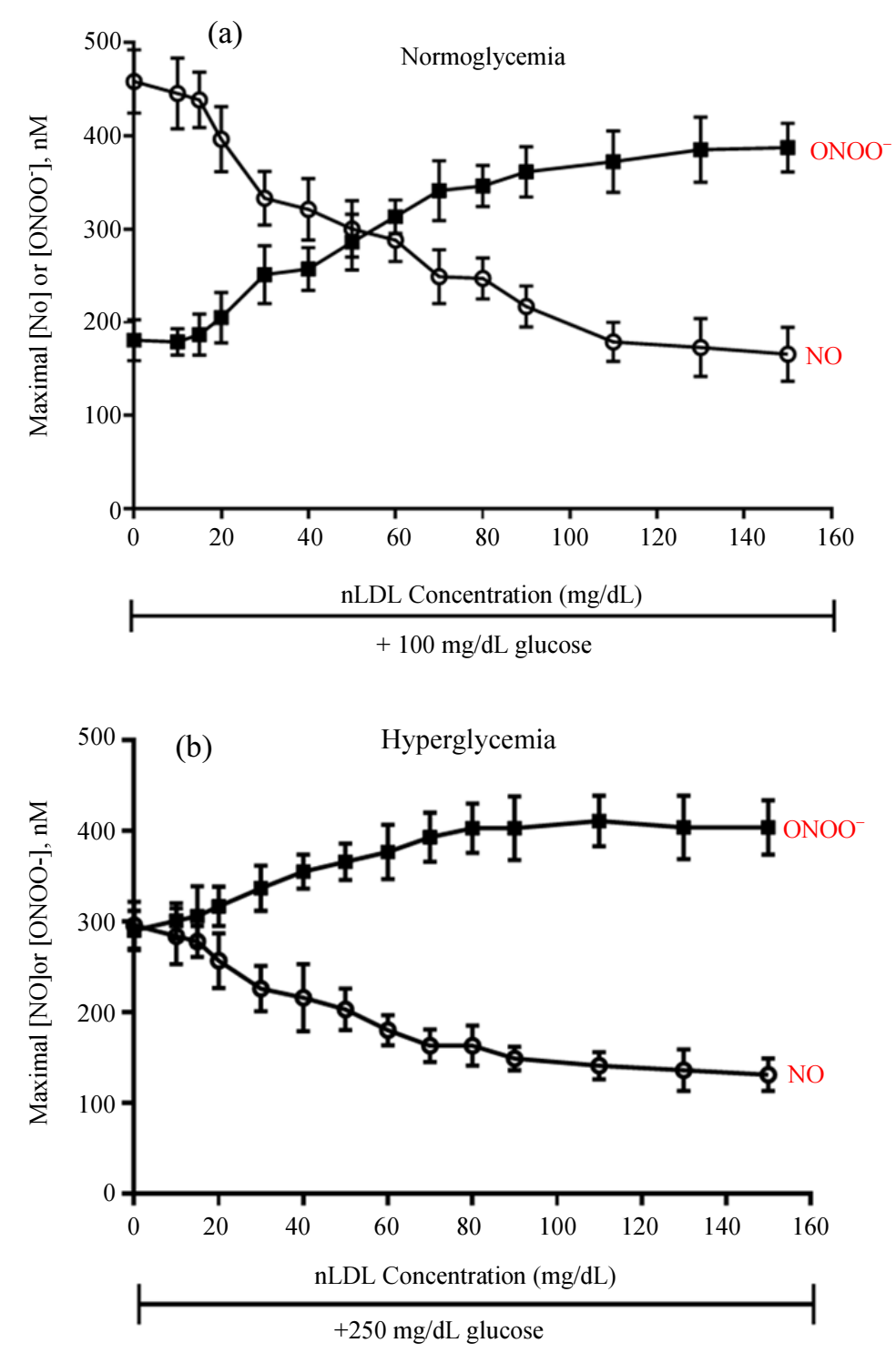

Fig. 2: Maximal nitric oxide (open circles) and peroxynitrite (solid square) concentrations at different LDL levels. HUVECs were incubated with normal glucose levels $(100 \mathrm{mg} / \mathrm{dL})$ (a) and elevated glucose $(250 \mathrm{mg} / \mathrm{dL})$ (b) in the presence of LDL, ranging from 10 to $150 \mathrm{mg} / \mathrm{dL}$

Effects of Progressive LDL Reductions on NO and ONOO- Release Under Normo- and Hyperglycemic Conditions

A significant effect of LDL changes on the release of $\mathrm{NO}$ and $\mathrm{ONOO}^{-}$was observed under normo- and hyperglycemic conditions (Fig. 2). With increasing LDL levels, NO decreased exponentially, while $\mathrm{ONOO}^{-}$ increased in a similar manner, under conditions of both normo- and hyperglycemia. However, the decrease of $\mathrm{NO}$ and the increase in $\mathrm{ONOO}^{-}$originated from significantly different levels. With normal glucose, maximal NO is $458 \pm 34$ while in hyperglycemia it is reduced to $296 \pm 26$. Also, in hyperglycemia, the level of
$\mathrm{ONOO}^{-}$is about $60 \%$ higher than with normal glucose. Therefore, the contribution of elevated LDL on the balance of [NO]/[ONOO$]$, is much more apparent under conditions of hyperglycemia.

The Effect of Progressive Elevation of LDL on [NO]/[ONOO'] Ratio Under Normal and Hyperglycemic Conditions

The $[\mathrm{NO}] /\left[\mathrm{ONOO}^{-}\right]$ratio is an indicator of eNOS efficiency and endothelial function. At higher $[\mathrm{NO}] /\left[\mathrm{ONOO}^{-}\right]$ratios, the bioavailability of cytoprotective $\mathrm{NO}$ is higher relative to cytotoxic $\mathrm{ONOO}^{-}$, the main component of nitroxidative stress. 

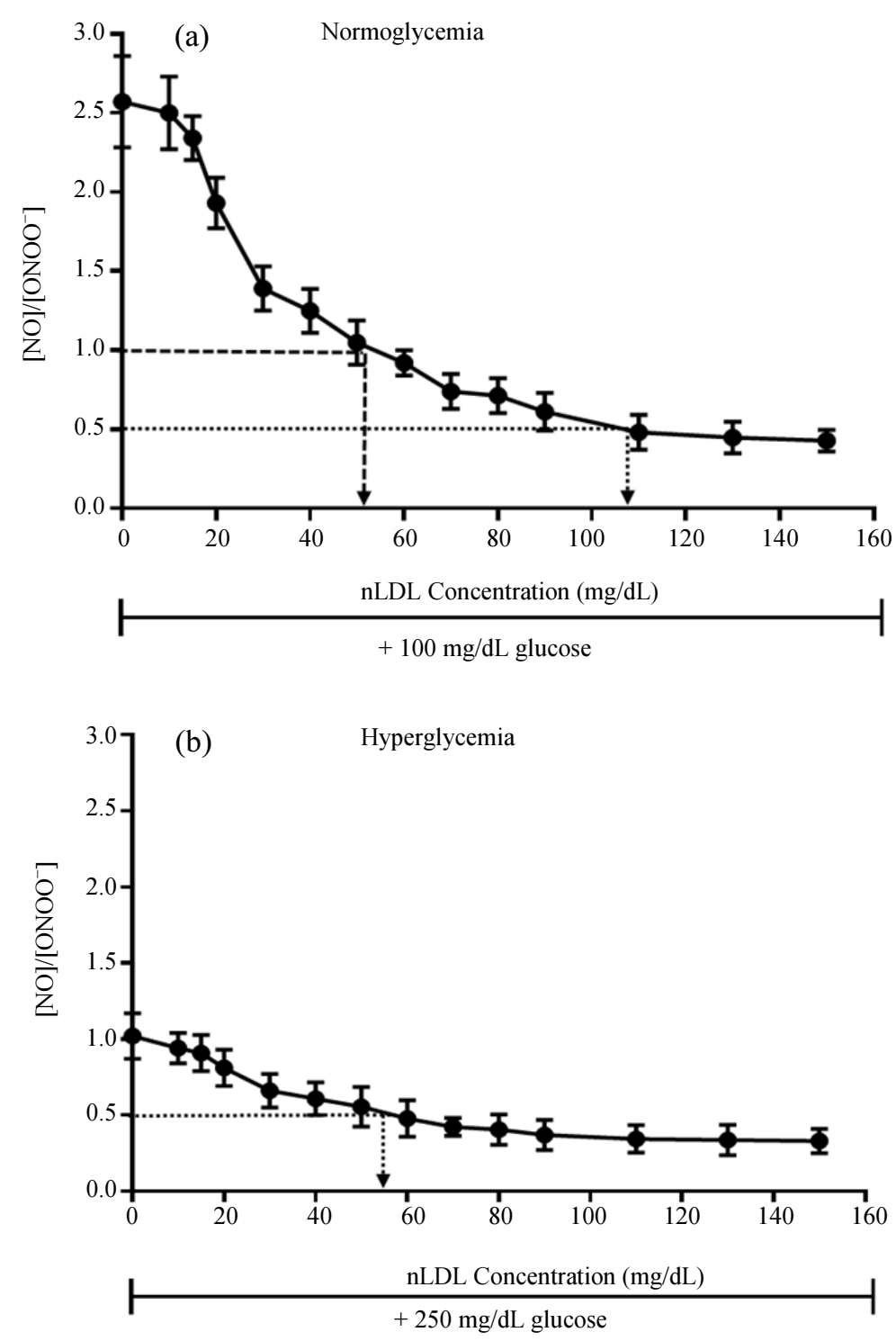

Fig. 3: The ratio of maximal $[\mathrm{NO}] /\left[\mathrm{ONOO}^{-}\right]$produced by HUVECs under normal glucose levels (100 mg/dL) (a) and elevated glucose $(250 \mathrm{mg} / \mathrm{dL})(\mathrm{b})$ in the presence of LDL, ranging from 10 to $150 \mathrm{mg} / \mathrm{dL}$. Arrows indicate extrapolated concentration of $\mathrm{LDL}$ at $[\mathrm{NO}] /\left[\mathrm{ONOO}^{-}\right]=1.0$ and $[\mathrm{NO}] /\left[\mathrm{ONOO}^{-}\right]=0.50$

The changes in the ratio of cytoprotective [NO] to cytotoxic $\left[\mathrm{ONOO}^{-}\right]$are depicted in Fig. 3. With normal glucose, [NO]/[ONOO$\left.{ }^{-}\right]$was $2.57 \pm 0.29$ and by adding $10 \mathrm{mg} / \mathrm{dL}$ LDL decreased this ratio slightly (by about $3 \%$ ). As the LDL lever further increased, [NO]/[ONOO$\left.{ }^{-}\right]$ reached a value 1.0 at about $50 \mathrm{mg} / \mathrm{dL}$. A [NO]/[ONOO'] ratio of 1.0 reflects on the equimolar concentrations of $\mathrm{NO}$ and $\mathrm{ONOO}^{-}$, which is the prime indicator of endothelial dysfunction and eNOS uncoupling. When $[\mathrm{NO}] /\left[\mathrm{ONOO}^{-}\right]$is below 1 , the cellular environment is controlled by oxidative stress, imposed by ONOO'. When $[\mathrm{NO}] /\left[\mathrm{ONOO}^{-}\right]=0.50$ and the concentration of $\mathrm{ONOO}^{-}$is nearly double to $\mathrm{NO}$, this is a sign of a further significant increase of oxidative stress. In normoglycemic conditions, this level of $[\mathrm{NO}] /\left[\mathrm{ONOO}^{-}\right]$ was reached at about $110 \mathrm{mg} / \mathrm{dL}$ of LDL (Fig. 3a).

Under hyperglycemic conditions, the ratio of $[\mathrm{NO}] /\left[\mathrm{ONOO}^{-}\right]$is already about 1.0 , which is about $160 \%$ lower than in normoglycemia. Therefore, in the presence of LDL, a further rapid decrease in $[\mathrm{NO}] /\left[\mathrm{ONOO}^{-}\right]$was observed. However, in contrast to normoglycemia, the effect of LDL is now imposed on a significantly dysfunctional endothelium. Therefore, the ratio of $[\mathrm{NO}] /\left[\mathrm{ONOO}^{-}\right]=0.5$ is reached at an $\mathrm{LDL}$ concentrations of about $50 \mathrm{mg} / \mathrm{dL}$ (Fig. 3b). A further increase in LDL, up to $150 \mathrm{mg} / \mathrm{dL}$, decreased $[\mathrm{NO}] /\left[\mathrm{ONOO}^{-}\right]$to about 0.40 , further increasing oxidative stress. Therefore, in hyperglycemia, the 
moderate oxidative stress in endothelium can be maintained only at LDL levels lower than $50 \mathrm{mg} / \mathrm{dL}$.

\section{Changes in eNOS Dimer Formation with Different Levels of LDL with Normal and Elevated Glucose}

In addition to measuring $\mathrm{NO}$ and $\mathrm{ONOO}^{-}$production with varying LDL levels, we also examined eNOS dimer formation with and without high glucose. Under normoglycemic conditions, uncoupling of eNOS and the concentration of dimer decreased gradually with an increase in LDL concentration (Fig. 4a). At about 110$120 \mathrm{mg} / \mathrm{dL}$ of LDL, the concentration of eNOS dimer was about $50 \%$ of that observed in the absence of LDL.
Under hyperglycemic conditions, eNOS dimer concentrations were already decreased by about $50 \%$. The addition of the effect of LDL on the dimeric eNOS markedly decreased its concentration. At a concentration of LDL around $30-50 \mathrm{mg} / \mathrm{dL}$, the dimer concentration dropped to about $15 \%$ compared to levels observed under normoglycemic conditions (Fig. 4b). There is a significant correlation between the presence of functional dimeric eNOS and the levels of [NO] and [ONOO$\left.{ }^{-}\right]$. It appears that an LDL level of $50 \mathrm{mg} / \mathrm{dL}$ has to be maintained in order to prevent a further decay of dimeric eNOS and endothelial function in hyperglycemia.
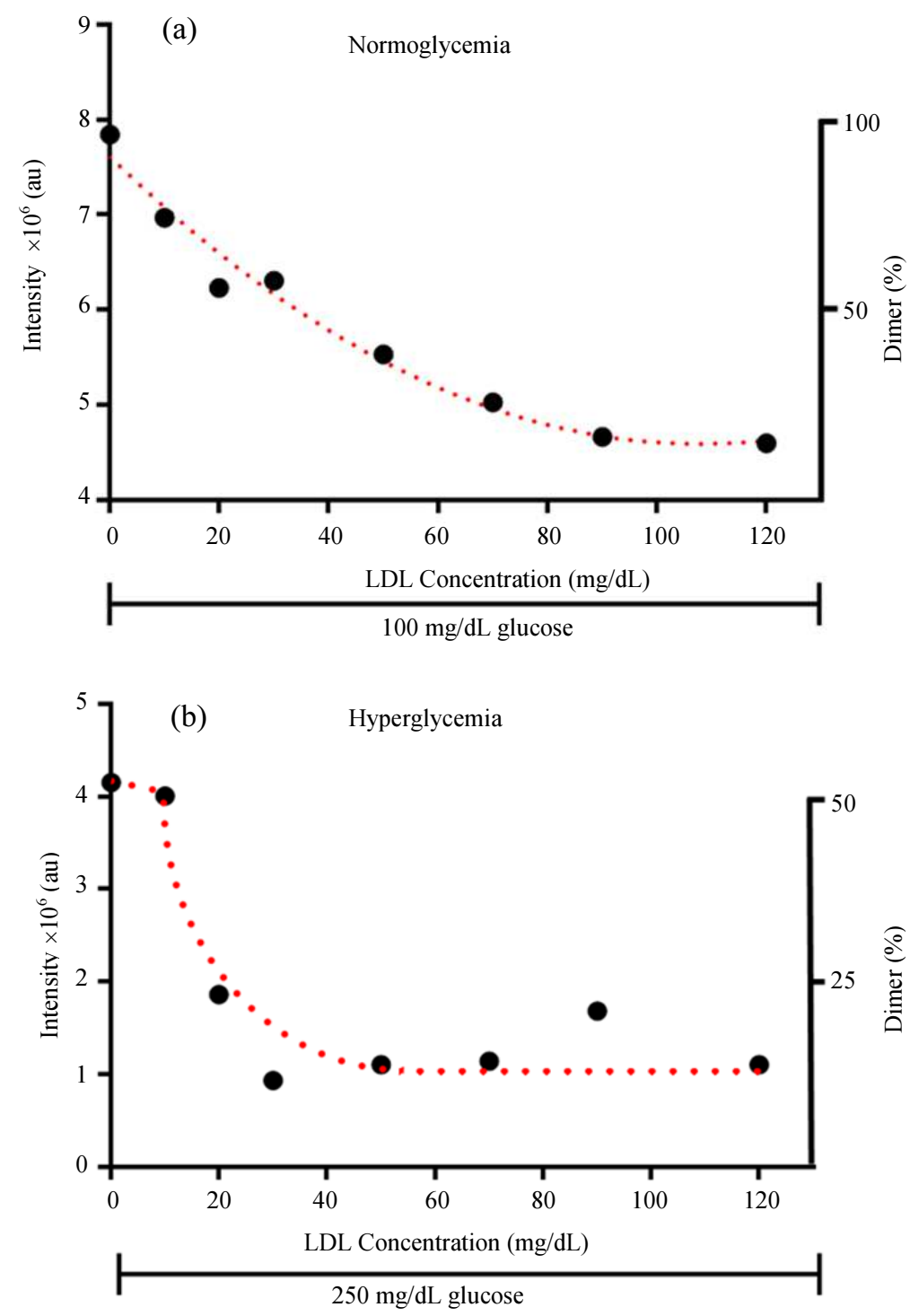

Fig. 4: Chemiluminescence intensity (arbitrary units) proportional to dimer concentration. As the function of LDL concentration. HUVECs were exposed to normal $(100 \mathrm{mg} / \mathrm{dL})$ (a) and elevated glucose levels $(250 \mathrm{mg} / \mathrm{dL})$ (b) for $1 \mathrm{hr}$, in the presence of different LDL concentrations. The dimer concentration measured under normoglycemic condition in the absence of LDL was assumed as $100 \%$ 


\section{Discussion}

The key finding from this study is that a reduction in LDL levels to very low levels is a necessity to limit endothelial dysfunction, oxidative stress and vascular damage under conditions of hyperglycemia. Even at LDL levels of $50 \mathrm{mg} / \mathrm{dL}$, which are well under the widely accepted target of $70 \mathrm{mg} / \mathrm{dL}$, we observed uncoupled eNOS as an efficient generator of $\mathrm{ONOO}^{-}$, especially under conditions of high glucose. These findings show that uncoupled, monomeric, eNOS can produce both $\mathrm{NO}$ and $\mathrm{O}_{2}^{-}$in close proximity which can react rapidly in a diffusion-controlled manner to produce $\mathrm{ONOO}^{-}$. $\mathrm{ONOO}^{-}$is a powerful biological oxidant that at high concentrations $(\sim 100 \mathrm{nM})$ can induce endothelial dysfunction (Chen et al., 2014; Stuehr et al., 2004; Vasquez-Vivar et al., 2003). NO is derived from the oxidation of L-arginine to L-citrulline by the enzymatic activity of eNOS. The activity of this electron transport enzyme requires calcium/calmodulin, flavin adenine dinucleotide, flavin mononucleotide and tetrahydrobiopterin $\left(\mathrm{BH}_{4}\right)$ as cofactors. Efficient eNOS activity (i.e., optimal generation of NO) is dependent upon the dimerization of the enzyme, along with enzymatic substrates and adequate co-factors, as these play key roles in stabilizing the functional dimer. When levels of substrates (L-arginine and $\mathrm{O}_{2}$ ) or co-factors, like $\mathrm{BH}_{4}$, are insufficient, uncoupled eNOS reduces molecular oxygen to superoxide (Harrison, 1997; Mason et al., 2009; Node et al., 1997). As a result, NO is scavenged by $\mathrm{O}_{2}^{-}$and $\mathrm{ONOO}^{-}$is generated while eNOS loses its cytoprotective actions within the cell that leads to endothelial dysfunction.

Using nanosensors, we measured the concentrations of $\mathrm{NO}$ and $\mathrm{ONOO}^{-}$from ECs following maximal stimulation with calcium ionophore. Based on these measurements, we were able to calculate the ratio of $[\mathrm{NO}] /\left[\mathrm{ONOO}^{-}\right]$, which reflects the balance between the concentrations of cytoprotective $\mathrm{NO}$ and cytotoxic $\mathrm{ONOO}^{-}$, the main source of nitroxidative stress. The balance of $[\mathrm{NO}] /\left[\mathrm{ONOO}^{-}\right]$is directly related to the relative dimeric and monomeric forms of eNOS. Under normal conditions, the $[\mathrm{NO}] /\left[\mathrm{ONOO}^{-}\right]$ratio in functional ECs varies from 2.5-5 and is indicative of efficient eNOS coupling. However, if the $[\mathrm{NO}] /\left[\mathrm{ONOO}^{-}\right]$ratio falls below this value, it is evidence of progressive eNOS uncoupling, resulting in low bioavailability of NO and an increase in oxidative stress, which leads to endothelial dysfunction. Peroxynitrite becomes the dominating factor when $[\mathrm{NO}] /\left[\mathrm{ONOO}^{-}\right]$falls below 1.0 , resulting in an unfavorable redox environment. If $[\mathrm{NO}] /\left[\mathrm{ONOO}^{-}\right]$ falls below 0.5 , it produces a severe oxidative stress that contributes to mechanisms of disease. ${ }^{24} \mathrm{We}$ found that it is not the absolute level of $\mathrm{NO}$ or $\mathrm{ONOO}^{-}$, but the ratio between them that is the determinant of the cellular redox environment (Burewicz et al., 2013; Mason et al., 2015; Khan et al., 2018; Sambe et al., 2018).
These studies indicate that large reductions in LDL are necessary to decrease eNOS uncoupling, thereby preventing the generation of $\mathrm{ONOO}^{-}$and preserving bioavailable NO. The redox balance between $\mathrm{NO}$ and $\mathrm{ONOO}^{-}$can be changed with decreases in LDL that lead to improved vasorelaxation of the cardiovascular system, while concomitantly reducing vasoconstriction induced by $\mathrm{ONOO}^{-}$and preventing nitroxidative damage to the endothelium. Previously, we also found improved eNOS function in obese Zucker rats by treating ECs with superoxide dismutase or an inhibitor of NADPH oxidase (Mason et al., 2011).

The most important finding of these studies is that hyperglycemia contributes strongly to endothelial dysfunction at LDL concentrations higher than $50 \mathrm{mg} / \mathrm{dL}$. Therefore, a significant reduction of LDL, even from the current target of $70 \mathrm{mg} / \mathrm{dL}$, is associated with reversal of endothelial damage under conditions of hyperglycemia.

Type $2 \mathrm{DM}$ in eNOS knockout mice results in vascular abnormalities typically associated with insulin resistance, including hyperinsulinemia (Duplain et al., 2001). Also, an endogenous eNOS inhibitor, Asymmetrical Dimethylarginine (ADMA), has been shown to reduce insulin sensitivity in a transgenic animal model (Shankar et al., 2000). This is consistent with the observation that patients with type $2 \mathrm{DM}$ have elevated plasma ADMA levels linked to reduced vascular compliance and glucose uptake (Stuhlinger et al., 2002). Impaired endothelial function has been shown to predict atherosclerotic disease progression and its clinical manifestations (Schächinger et al., 2000).

The clinical implications of this study suggest that current LDL target levels may not be aggressive enough to fully restore vascular function and reverse atherosclerosis. Despite reducing the progression of coronary atherosclerosis and associated clinical events, statins do not fully address residual CV risk even in patients who achieve optimal LDL levels (Fruchart., 2014). Consistent with the observations in this study, there is now evidence that lipid therapy beyond statins can help further reduce $\mathrm{CV}$ risk by lowering LDL levels well below target levels (Bosi, 2009; Kinaan et al., 2015).

Limitations of this analysis include uncertainty about whether these results are directly applicable to humans with type $2 \mathrm{DM}$. This was a cell culture study and therefore the results need to be confirmed in human subjects.

\section{Conclusion}

This study showed a strong link between LDL reduction and improved eNOS function in hyperglycemia. Lowering LDL levels below $50 \mathrm{mg} / \mathrm{dL}$ significantly improved eNOS coupling, resulting in increased NO production and mitigated production of cytotoxic $\mathrm{ONOO}^{-}$in hyperglycemic cells, while the same benefits, albeit in a more moderate manner, were observed under normoglycemic conditions at LDL levels below $110 \mathrm{mg} / \mathrm{dL}$. Taken together, these results illustrate 
the importance of LDL lowering in patients with comorbid CV risk factors like DM.

\section{Acknowledgment}

A special thanks to Collin Arocho for his technical support provided in this manuscript.

\section{Funding Information}

This study was supported by an independent, investigator-initiated grant from Amgen. Dr. Malinski was supported by the Marvin and Ann Dilley White Endowment and the Ita Pluta-Plotowska Endowment Fund at the Ohio University Foundation.

\section{Authors Contributions}

R. Preston Mason: Was responsible for project design and writing.

Hazem Dawoud: Was responsible for data collection and analysis.

Samuel C.R. Sherratt: Was responsible for data collection and analysis

Michael R. Wagner: Was responsible for data collection and analysis.

Tadeusz Malinski: Was responsible for project design, writing and managing the experiments.

\section{Ethics}

This article is original and contains unpublished material. The corresponding author confirms that all of the other authors have read and approved the manuscript and no ethical issues involved.

\section{References}

Benson, M.A., H. Batchelor, S. Chuaiphichai, J. Bailey and H. Zhu et al., 2013. A pivotal role for tryptophan 447 in enzymatic coupling of human endothelial Nitric Oxide Synthase (eNOS): Effects on tetrahydrobiopterin-dependent catalysis and eNOS dimerization. J. Biol. Chem., 288: 29836-29845.

DOI: $10.1074 /$ jbc.M1 13.493023

Bonetti, P.O., L.O. Lerman and A. Lerman, 2003. Endothelial dysfunction: A marker of atherosclerotic risk. Arteriosclerosis Thrombosis Vascular Biol., 23: 168-175.

DOI: 10.1161/01.ATV.0000051384.43104.FC

Bosi, E., 2009. Metformin--the gold standard in type 2 diabetes: What does the evidence tell us? Diabetes Obes. Metab, 11: 3-8.

DOI: $10.1111 / \mathrm{j} .1463-1326.2008 .01031 . x$
Burewicz, A., H. Dawoud, L.L. Jiang and T. Malinski, 2013. Nitric oxide/peroxynitrite redox imbalance in endothelial cells measured with amperometric nanosensors. Am. J. Analytical Chem., 4: 30-36. DOI: 10.4236/ajac.2013.410A1004

Cavender, M.A., P.G. Steg, S.C. Smith, Jr., K. Eagle and E.M. Ohman et al., 2015. Impact of diabetes mellitus on hospitalization for heart failure, cardiovascular events and death: Outcomes at 4 years from the Reduction of Atherothrombosis for Continued Health (REACH) registry. Circulation, 132: $923-31$

DOI: 10.1161/CIRCULATIONAHA.114.014796

Chen, W., H. Xiao, A.N. Rizzo, W. Zhang and Y. Mai et al., 2014. Endothelial nitric oxide synthase dimerization is regulated by heat shock protein 90 rather than by phosphorylation. PLoS One, 9: e105479-e105479.

DOI: 10.1371/journal.pone.0105479

Cholesterol Treatment Trialists, P.M. Kearney, L. Blackwell, R. Collins and A. Keech et al., 2008. Efficacy of cholesterol-lowering therapy in 18,686 people with diabetes in 14 randomised trials of statins: A meta-analysis. Lancet, 371: 117-25.

DOI: 10.1016/S0140-6736(08)60104-X

Colhoun, H.M., D.J. Betteridge, P.N. Durrington, G.A. Hitman and H.A.W. Neil et al., 2004. Primary prevention of cardiovascular disease with atorvastatin in type 2 diabetes in the Collaborative Atorvastatin Diabetes Study (CARDS): Multicentre randomised placebo-controlled trial. Lancet, 364: 685-696.

Consentino, F., S. Bonetti, R. Rehorik, M. Eto and G. Werner-Felmayer et al., 2002. Nitric-oxidemediated relaxations in salt-induced hypertension: Effect of chronic beta1-selective receptor blockade. J. Hypertension, 20: 421-28. DOI: $10.1016 / \mathrm{S} 0140-6736(04) 16895-5$

Dawoud, H. and T. Malinski, 2018. A nanomedical approach to understanding the mechanism of endothelial function and dysfunction-Clinical implications. J. Nanomed., 1: 1006-1006.

Duplain, H., R. Burcelin, C. Sartori, S. Cook and M. Egli et al., 2001. Insulin resistance, hyperlipidemia and hypertension in mice lacking endothelial nitric oxide synthase. Circulation, 104: 342-5.

DOI: $10.1161 / 01 . C I R .104 .3 .342$

Fruchart, J.C., J. Davignon, M.P. Hermans, K. AlRubeaan and P. Amarenco et al., 2014. Residual macrovascular risk in 2013: what have we learned? Cardiovascular Diabetol., 13: 26-26. DOI: $10.1186 / 1475-2840-13-26$

Harrison, D.G., 1997. Cellular and molecular mechanisms of endothelial cell dysfunction. J. Clin. Investigat., 100: 2153-2157. DOI: 10.1172/JCI119751 
Harrison, D.G., P.C. Freiman, M.L. Armstrong, M.L. Marcus and D.D. Heistad, 1987. Alterations of vascular reactivity in atherosclerosis. Circulat. Res., 61: 74-80. DOI: 10.1161/res.61.5_supplement.ii-74

Khan, A., H. Dawoud and T. Malinski, 2018. Nanomedical studies of the restoration of nitric oxide/peroxynitrite balance in dysfunctional endothelium by 1,25-dihydroxy vitamin D3-clinical implications for cardiovascular diseases. Int. J. Nanomed., 13: 455-66. DOI: 10.2147/Ijn.S152822

Kinaan, M., H. Ding and C.R. Triggle, 2015. Metformin: An old drug for the treatment of diabetes but a new drug for the protection of the endothelium. Med. Princ Pract., 24: 401-15. DOI: 10.1159/000381643

Kurioka, S., K. Koshimura, Y. Murakami, M. Nishiki and Y. Kato, 2000. Reverse correlation between urine nitric oxide metabolites and insulin resistance in patients with type 2 diabetes mellitus. Endocrine J., 47: 77-81.

Laufs, U., V. La Fata, J. Plutzky and J.K. Liao, 1998. Upregulation of endothelial nitric oxide synthase by HMG CoA reductase inhibitors. Circulation, 97: 1129-35.

Liao, J.K., 1998. Endothelium and acute coronary syndromes. Clin. Chem., 44: 1799-808.

Malinski, T. and Z. Taha, 1992. Nitric oxide release from a single cell measured in situ by a porphyrinicbased microsensor. Nature, 358: 676-676. DOI: $10.1038 / 358676 \mathrm{a} 0$

Mason, R.P., J.J. Corbalan, R.F. Jacob, H. Dawoud and T. Malinski, 2015. Atorvastatin enhanced nitric oxide release and reduced blood pressure, nitroxidative stress and rantes levels in hypertensive rats with diabetes. J. Physiol. Pharmacol., 66: 65-72.

Mason, R.P., L. Kalinowski, R.F. Jacob, A.M. Jacoby and T. Malinski, 2005a. Nebivolol reduces nitroxidative stress and restores nitric oxide bioavailability in endothelium of black Americans. Circulation, 112: 3795-801. DOI: 10.1161/circulationaha.105.556233

Mason, R.P., R.F. Jacob, R. Kubant, M.F. Walter and A. Bellamine et al., 2011. Effect of enhanced glycemic control with saxagliptin on endothelial nitric oxide release and CD40 levels in obese rats. J. Atherosclerosis Thrombosis, 18: 774-83. DOI: $10.5551 /$ jat.7666

Mason, R.P., R. Kubant, G. Heeba, R.F. Jacob and C.A. Day et al., 2008. Synergistic effect of amlodipine and atorvastatin in reversing LDL-induced endothelial dysfunction. Pharmaceutical Res., 25: 1798-806. DOI: 10.1007/s1 1095-007-9491-1

Mason, R.P., R. Kubant, R.F. Jacob, P. Malinski and X. Huang et al., 2009. Loss of arterial and renal nitric oxide bioavailability in hypertensive rats with diabetes. Am. J. Hypertens., 22: 1160-66.

DOI: 10.1038 ajh.2009.163
Mason, R.P., M.F. Walter, C.A. Day and R.F. Jacob, 2005b. Intermolecular differences for HMG-CoA reductase inhibitors contribute to distinct pharmacologic and pleiotropic actions. Am. J. Cardiol., 96: 11F-23F.

DOI: 10.1016/j.amjcard.2005.06.008

Node, K., M. Kitakaze, H. Yoshikawa, H. Kosaka and M. Hori, 1997. Reduced plasma concentrations of nitrogen oxide in individuals with essential hypertension. Hypertension, 30: 405-408.

DOI: 10.1161/01.HYP.30.3.405

Oemar, B.S., M.R. Tschudi, N. Godoy, V. Brovkovich and T. Malinski et al., 1998. Reduced endothelial nitric oxide synthase expression and production in human atherosclerosis. Circulation, 97: 2494-8. DOI: 10.1161/01.CIR.97.25.2494

Paniagua, O.A., M.B. Bryant and J.A. Panza, 2001. Role of endothelial nitric oxide in shear stress-induced vasodilation of human microvasculature: Diminished activity in hypertensive and hypercholesterolemic patients. Circulation, 103: 1752-1758. DOI: 10.1161/01.CIR.103.13.1752

Panza, J.A., A.A. Quyyumi, J.E. Brush and S.E. Epstein, 1990. Abnormal endothelium-dependent vascular relaxation in patients with essential hypertension. New Engl. J. Med., 323: 22-27. DOI: $10.1056 /$ NEJM199007053230105

Sabatine, M.S., R.P. Giugliano, A.C. Keech, N. Honarpour and S.D. Wiviott et al., 2017. Evolocumab and clinical outcomes in patients with cardiovascular disease. New Engl. J. Med., 376: 1713-1722. DOI: 10.1056/NEJMoa1615664

Sambe, T., R.P. Mason, H. Dawoud, D.L. Bhatt and T. Malinski, 2018. Metformin treatment decreases nitroxidative stress, restores nitric oxide bioavailability and endothelial function beyond glucose control. Biomed. Pharmacother., 98: 149-156.

DOI: 10.1056/NEJMoa1615664

Schächinger, V., M.B. Britten and A.M. Zeiher, 2000. Prognostic impact of coronary vasodilator dysfunction on adverse long-term outcome of coronary heart disease. Circulation, 101: 1899-1906. DOI: 10.1161/01.CIR.101.16.1899

Shankar, R.R., Y. Wu, H.Q. Shen, J.S. Zhu and A.D. Baron, 2000. Mice with gene disruption of both endothelial and neuronal nitric oxide synthase exhibit insulin resistance. Diabetes, 49: 684-687.

Stamler, J., O. Vaccaro, J.D. Neaton and D. Wentworth, 1993. Diabetes, other risk factors and 12-yr cardiovascular mortality for men screened in the multiple risk factor intervention trial. Diabetes Care, 16: 434-444. 
Stuehr, D.J., J. Santolini, Z.Q. Wang, C.C. Wei and S. Adak, 2004. Update on mechanism and catalytic regulation in the NO synthases. J. Biol. Chem., 279: 36167-3670. DOI: 10.1074/jbc.R400017200

Stuhlinger, M.C., F. Abbasi, J.W. Chu, C. Lamendola and T.L. McLaughlin et al., 2002. Relationship between insulin resistance and an endogenous nitric oxide synthase inhibitor. J. Am. Med. Assoc., 287: 1420-1426. DOI: 10.1001/jama.287.11.1420

Treasure, C.B., J.L. Klein, W.S. Weintraub, J.D. Talley and M.E. Stillabower et al., 1995. Beneficial effects of cholesterol-lowering therapy on the coronary endothelium in patients with coronary artery disease. New Engl. J. Med., 332: 481-487. DOI: 10.1056/NEJM199502233320801

Vasquez-Vivar, J., B. Kalyanaraman and P. Martasek, 2003. The role of tetrahydrobiopterin in superoxide generation from eNOS: Enzymology and physiological implications. Free Radic. Res., 37: 121-127. DOI: 10.1080/1071576021000040655

Williams, S.B., J.A. Cusco, M.A. Roddy, M.T. Johnstone and M.A. Creager, 1996. Impaired nitric oxide-mediated vasodilation in patients with noninsulin-dependent diabetes mellitus. J. Am. Coll. Cardiol., 27: 567-574.

\author{
Abbreviations and Units \\ AMDA Asymmetric dimethylarginine \\ BH4 Tetrahydrobiopterin \\ CaI Calcium ionophore \\ CARDS Collaborative atorvastatin diabetes study \\ CTT \\ CVD \\ DM \\ EC \\ eNOS \\ HBSS \\ Cholesterol treatment trialists \\ Cardiovascular disease \\ Diabetes mellitus \\ Endothelial cell \\ Hank's balanced salt solution \\ HUVECs Human umbilical vein endothelial cells \\ LDL \\ Low-density lipoprotein \\ LT-SD-PAGE Low temperature sodium dodecyl sulfate \\ polyacrylamide gel electrophoresis \\ NO Nitric oxide \\ O2- Superoxide \\ ONOO- Peroxynitrite \\ RIPA Radioimmunoprecipitation assay buffer \\ SDS-PAGE Sodium dodecyl sulfate polyacrylamide \\ gel electrophoresis
}

